\title{
Effects of Processing Parameters on Properties of SiCp/Al Composites
}

\author{
Qun HUI ${ }^{1 \mathrm{a}}$, Dong Yuan SHAO ${ }^{\mathrm{b}}$, Chun Mei LI' ${ }^{\mathrm{c}}$, Jing Jing $\mathrm{CHEN}^{\mathrm{d}}$, Xiao $\mathrm{LI}^{\mathrm{e}}$ and $\mathrm{Nan} \mathrm{Pu}$ \\ CHENG $^{\mathrm{f}}$
}

Faculty of Materials and Energy, Southwest University, Chongqing 400715, China

aqhui01@swu.edu.cn bsdy1988719@swu.edu.cn, ${ }^{1} 1 \mathrm{lcm} 1998 @$ swu.edu.cn,

d cjj911013@swu.edu.cn, ${ }^{\mathrm{e}} 1 \mathrm{x} 123 \mathrm{ppp} @$ swu.edu.cn ${ }^{\mathrm{f}}$ Corresponding author:cheng_np@swu.edu.cn

\begin{abstract}
The effects of hot pressing and hot extrusion temperatures on the properties of $12 \% \mathrm{SiCp} / 6066 \mathrm{Al}$ (volume fraction) composites fabricated by powder metallurgy have been studied. The experimental results indicate that the hot extrusion, an essential stage of powder metallurgy to produce this sort of particle reinforced metal matrix composites, can redistribute $\mathrm{SiC}$ particles in metal matrix and refine the matrix grain size, and that the hot pressing can improve the interfacial cohesion strength between $\mathrm{SiC}$ particles and metal matrix. When hot-pressed at temperatures slightly higher than the solidus temperature of the composite and hot-extruded at lower temperatures, the composites are stronger due to the high metal matrix strength and interfacial cohesion. The optimum parameters of hot pressing and hot extrusion in the composites are 560 and $430{ }^{\circ} \mathrm{C}$, respectively.
\end{abstract}

\section{Introduction}

$\mathrm{SiC}$ particle reinforced $\mathrm{Al}$ matrix composites $(\mathrm{SiCp} / \mathrm{Al})$ can be fabricated by general fabricating methods, such as powder metallurgy (PM), squeeze casting, pressural or pressureless infiltration and spray forming, etc $[1,2]$. The composites tend to be loose due to the poor wettability between $\mathrm{SiC}$ and $\mathrm{Al}$ matrix. To improve their shaping properties, the second plastic processing, such as the hot extrusion technique, is needed[2,3]. Corbin and Lewandowski have investigated the effects of $\mathrm{SiC}$ particle distribution on the mechanical properties of $\mathrm{SiCp} / \mathrm{Al}$ composites[4]. Zhou, et al, has studied the effects of the hot extrusion process on the microstructures and properties of $\mathrm{SiCp} / \mathrm{Al}$ composites[3]. These results indicate that the second processing is essential to improve the forming properties, and especially the hot extrusion can ameliorate the microstructures and mechanical properties of $\mathrm{SiCp} / \mathrm{Al}[3]$. During the process of producing composites by PM method, extra time and energy are needed in normal pressure sintering due to the oxidation layer on $\mathrm{Al}$ matrix powders. Thus, the sintering of the composites should be carried out at high temperature with high pressure to enhance the atomic diffusion effect and improve the sintering effects[5]. All

*Corresponding author:qhui01@swu.edu.cn 
these reveal that the forming temperatures seriously influence the mechanical properties of $\mathrm{SiCp} / \mathrm{Al}$ composites. However, there is hardly any report addressing the effects of the combination of hot pressing and hot extrusion on the properties of $\mathrm{SiCp} / \mathrm{Al}$ composites.

In the current work, to control the microstructures and interfaces, the effects of hot pressing and hot extrusion on the microstructures and mechanical properties of $12 \% \mathrm{SiCp} / \mathrm{Al}$ composite produced by PM route are studied and the optimal technologic parameters have been obtained.

\section{Materials and Experimental Procedures}

\subsection{Materials and Preparation}

The sharp $\alpha$-SiC particles with an average size of $5 \mu \mathrm{m}$ and the atomized Al alloy particles with particle size less than $45 \mu \mathrm{m}$ (nominal composition (wt\%): Al-1.4Mg-1.22Si-1.19Cu-0.92Mn, namely 6066Al) are used as reinforcements and metal matrix, respectively. The preparation of the composite include pretreatment process (oxidation, acid picking and alkali cleaning) of $\mathrm{SiC}$ particles, mixing, cold isostatic pressing, degassing, sintering at normal pressure, hot pressing and hot extrusion. The cold isostatic pressed compacts are sintered at $500{ }^{\circ} \mathrm{C}$ for $16 \mathrm{~h}$. Then the sintered bodies are treated by hot pressing (HP) only, hot extrusion (HE) only and both hot pressing and hot extrusion at different temperatures, respectively. The hot pressing was carried out in a steel cylinder at a unitary pressure of $400 \mathrm{MP}$ for $1 \mathrm{~h}$ and then hot extruded with the reduction ratio 20:1 and dam speed $2 \mathrm{~mm} / \mathrm{s}$.

\subsection{Properties tests and microstructure characterization}

The mechanical properties of the composites were tested on a GALDABINI SUN 5 testing machine at room temperature. Fracture surfaces of the composites were observed with a KYKY-2800 scanning electron microscopy and metallographs with a PMG3 optical microscopy and interfacial structures with a JEOL 2010 Transmission electron microscopy.

\subsection{Experimental Results and Discussion}

\subsubsection{Metallograph Analysis}

Figs.1(a) and (b) respectively show the fractograph and metallograph of the cold isostatic pressed green compacts of the $\mathrm{SiCp} / \mathrm{Al}$ composites. Fig.1(a) macroscopically shows that the reinforcement $\mathrm{SiC}$ particles homogeneously adhere to the matrix powder particles. In Fig. 1(b), however, several $\mathrm{SiC}$ particles microscopically accumulated together in the gaps among the larger size matrix powder particles, and many connected holes existed in the green compacts. The measured relative density of the green compacts was about $81.2 \%$. Figs.1(c)-(f) display the metallographs of the composite in the processes of normal pressure sintering, hot pressing and hot extrusion, respectively. And the corresponding relative densities were $83.4 \%, 91.3 \%$ and $99.9 \%$. The sintering process has few effects on the relative density. The hot pressing process can lightly destroy the network-like distribution of SiC particles at the edges of $\mathrm{Al}$ matrix powder particles and improve the relative density. However, the hot extrusion process can greatly improve the relative density and regulate the 
distribution of $\mathrm{SiC}$ particles due to the large flow strain[6]. It is significant that the grain size of $\mathrm{Al}$ matrix in the composite is smaller than that of the matrix alloy produced by the same route, explained by the increased effective reduction ratio and cutting action due to the presence of tough particles in metal matrix. ${ }^{6}$ From Figs.1(c)-(f), one can find that the processes of hot pressing and hot extrusion have great influence on the microstructures of the composite, and the hot extrusion process is an essential procedure in preparing this sort of particle reinforced composites. Furthermore, the increased relative density, grain refinement in the metal matrix composite and uniform distribution of reinforcements will improve the mechanical properties of the particle reinforced composite[3,6].

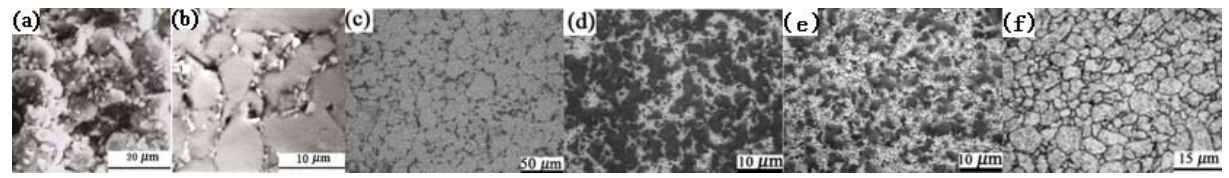

Fig. 1 Microstructures of $10 \% \mathrm{SiCp} / 6066 \mathrm{Al}$ at different stages

(a)Fracture surface of cold-compacted sample; (b)Metallograph of cold-compacted sample;(c) sintered; (d)HP; (e)hot extruded; (f) Hot extruded AA6066 alloy

\subsubsection{Mechanical Properties}

Fig.2 is the DSC analysis of the $\mathrm{SiCp} / \mathrm{Al}$ composite prepared by sintering at normal pressure and hot extrusion. The aim is to find the most favorable temperatures for hot pressing and hot extrusion.

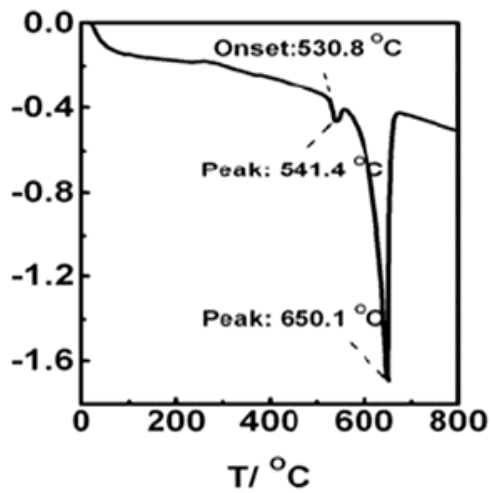

Fig. 2. DSC analysis of the $12 \% \mathrm{SiCp} / 6066 \mathrm{Al}$ composite

Fig. 2 indicates that the temperatures of solidus and liquidus of the composites are 541.4 and $650.1{ }^{\circ} \mathrm{C}$, respectively. Therefore, the mechanical properties of the composites prepared by hot pressing at $480,520,560$ and $580^{\circ} \mathrm{C}$ and hot extrusion at $380,430,480,530$ and $580^{\circ} \mathrm{C}$ were investigated. Fig. 3 shows the average mechanical properties of the composites prepared at different temperatures of hot pressing and hot extrusion. 


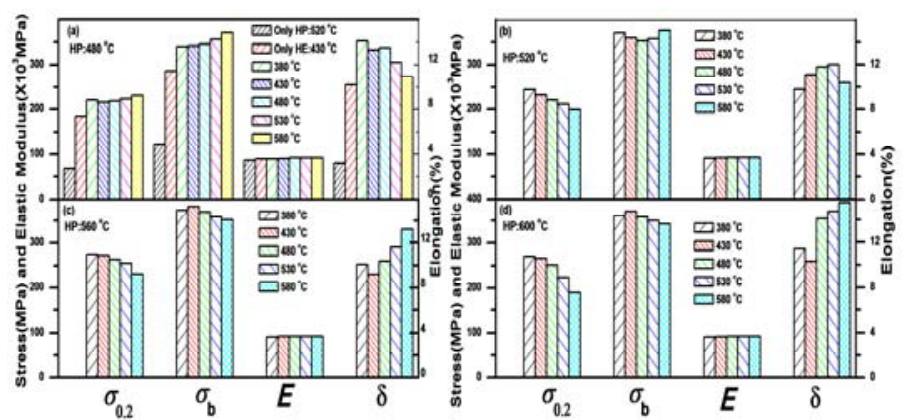

Fig. 3. Temperature parameters and properties of $\mathrm{SiCp} / \mathrm{Al}$ composites

\subsubsection{Fracture Surface Analysis}

Fig.4 shows the typical fracture surfaces of $\mathrm{SiCp} / \mathrm{Al}$ composites prepared by different processes. In the composites fabricated by HP only, the SiC particles were obviously clustered and lots of holes were generated in the composite with weak-bonded $\mathrm{SiC} / \mathrm{Al}$ interfaces. In the composites fabricated by both hot pressing and hot extrusion at low temperatures, the $\mathrm{SiC}$ particles are homogeneously distributed in the $\mathrm{Al}$ matrix. However, some exposed $\mathrm{SiC}$ particles and some pits with the size similar to that of the $\mathrm{SiC}$ particles can be seen in the fracture surface. It stems from the interfacial decohesion and indicates that the interfacial bond is weak. In the composites hot-pressed at $560^{\circ} \mathrm{C}$, a little higher than the solidus temperature, and hot-extruded at the universal temperature of $430^{\circ} \mathrm{C}$, the $\mathrm{Al}$ matrix are plastically deformed while the reinforcements are cracked, indicating that $\mathrm{SiC}$ particles are distributed homogeneously in matrix and the interfacial bond is strong. In the composites hot-pressed and hot-extruded both at $580^{\circ} \mathrm{C}$ at which the matrix alloy is in the semi-solid state, the metal matrix was ductile fractured without $\mathrm{SiC}$ particles being seen in the fracture surface. This indicates that the strength of the metal matrix is low while the $\mathrm{SiC} / \mathrm{Al}$ interfacial cohesion is strong in the composite.

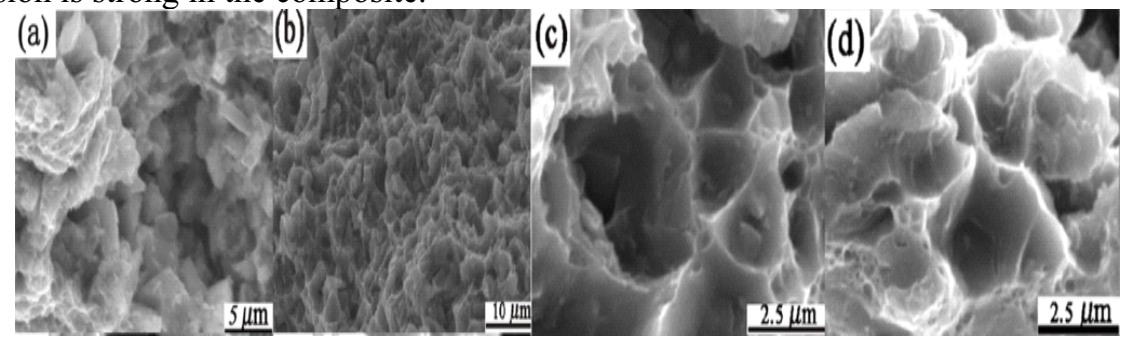

Fig. 4 Typical fracture surfaces of $\mathrm{SiCp} / 6066 \mathrm{Al}$ composites

(a) $\mathrm{HP}$ at $520{ }^{\circ} \mathrm{C}$; (b) $\mathrm{HP}$ at $480^{\circ} \mathrm{C}$ and extruded at $380^{\circ} \mathrm{C}$;

(c) $\mathrm{HP}$ at $560^{\circ} \mathrm{C}$ and extruded at $430{ }^{\circ} \mathrm{C}$; (d) $\mathrm{HP}$ at $600{ }^{\circ} \mathrm{C}$ and extruded at $580{ }^{\circ} \mathrm{C}$

\subsubsection{SiC/AI Interface TEM Analysis}

Fig5(a) shows the $\mathrm{SiC} / \mathrm{Al}$ interfaces of the composites produced by being sintered at normal pressure and hot pressed at $520{ }^{\circ} \mathrm{C}$ without hot extrusion (see the fracture surface in Fig.4(a)), while Fig.5(b) gives the interface image of the composite prepared by being sintered at normal pressure, $\mathrm{HP}$ at $560^{\circ} \mathrm{C}$ and extruded at $430^{\circ} \mathrm{C}$ (see the fracture surface in Fig.4(c)), respectively. From Fig5(a), it indicates that the $\mathrm{SiC}$ particles were clustered and the interfacial bond was weak, which cased the poor mechanical properties of the composites (also see Fig.3). However, in Fig5.(b), it was found that the interfaces less than 2-nm 
thickness are clean and strongly bonded due to the atomic diffusion during the HP process for a long time.

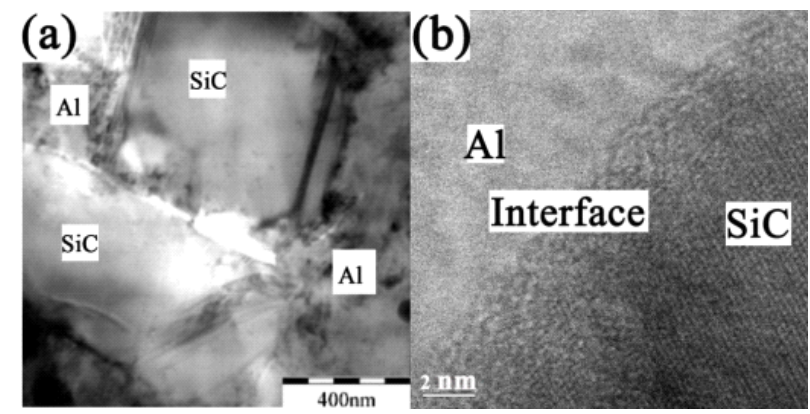

Fig. 5. Interfaces of the $\mathrm{SiCp} / \mathrm{Al}$ composites produced by sintering at normal pressure and $\mathrm{HP}$ (a) at $520{ }^{\circ} \mathrm{C}$ without $\mathrm{HE}$; (b) at $560^{\circ} \mathrm{C}$ and extruded at $430{ }^{\circ} \mathrm{C}$

\section{Discussions}

In Fig.1, the $\mathrm{SiC}$ particles much smaller than matrix alloy powders were not homogeneous and usually clustered in the cold isostatic pressed green compacts, leading to a high cavity ratio. After sintering for 16 hours at $500^{\circ} \mathrm{C}$ and normal pressure, the cavity ratio was decreased, contributing to the recovery of sintering necks. ${ }^{5}$ Due to the weak flowing, SiC particles still remain at the edges of Al powders. When hot-pressed, the metal matrix would deform plastically under high pressure, increasing the relative density and lightly regulating the positions of $\mathrm{SiC}$ particles and improving the distribution of $\mathrm{SiC}$ particles in matrix. However, due to the small deformability and weak flow of matrix, the redistribution of $\mathrm{SiC}$ was poor and some were clustered, leading to the lower strength, elastic modulus and elongation to failure of the composites.

The metallograph indicates that hot extrusion can effectively regulate the redistribution of $\mathrm{SiC}$ particles for the reason that the matrix deforms severely and the $\mathrm{SiC}$ particles flow and disperse in the matrix during the hot extrusion process[3,4,6]. Fig.1 (e) manifests that with the better redistribution of $\mathrm{SiC}$ and the grain refinement of matrix, the mechanical properties of the composite produced by hot extrusion only is much higher than those of the composite produced by hot pressing only. Hence, the hot extrusion is an essential procedure of PM method to prepare the composites.

As the solidus temperature $540^{\circ} \mathrm{C}$ shown in Fig. 3 is considered to be the boundary between the low and high temperature regions, the strength of the composite hot-pressed at high temperature and hot-extruded at low temperature is highest. The composite hot-pressed at low temperature and hot-extruded at high temperature has lower tensile strength, and that the tensile strength values of the other composites are at the lowest levels. The enhanced temperature for hot-pressing or hot-extrusion will heighten the atomic diffusion of Al matrix in $\mathrm{SiC}$ particle surfaces to form a strong interfacial bond[5]. But with the increasing temperature, the metal matrix will lose their original strength and decrease the strength of the composites since that the mechanical properties of the composites are dependent on those of the matrix. As hot-pressed at very high temperature (e.g. $600^{\circ} \mathrm{C}$ in the current experiments) for a long time, the strong atomic diffusion will cause a thick interfacial layer which is also to decrease the strength of composites. Generally, if the extrusion speed is fast (namely, the holding time at high temperature is very short), the hot extrusion process is insufficient to fulfill the atomic diffusion for interfacial bonding. When the green compact is hot-pressed under high pressure, the Al powders become soft. Therefore, the Al powder surface oxide layers will be broken due to the pressure effect, and the exposed fresh surfaces will be 
directly contacted with $\mathrm{SiC}$ surfaces or other Al powder surfaces. Either will shorten the distance of atomic diffusion and be beneficial to increase the interfacial cohesion. As the hot pressing temperature is selected at $560^{\circ} \mathrm{C}$ in the current work, the materials is in the low temperature region of semi-solid state, ensuring that the atomic diffusion is sufficient as well as the matrix powders have not lose their strength too much, at the same, the atomic diffusion will form a very thin interface layer with strong bond force. Under the condition that the interfaces are well bonded, the hot extrusion temperature of the composite can be same as that of the matrix alloy $\left(430^{\circ} \mathrm{C}\right.$ is reasonable in the current experiment). Consequently, the strength of the composite is highest. In Figs.3(a) and (b), as the green compact is hot-pressed at lower temperature and hot-extruded at higher temperature, e.g. the semi-solid temperature of $580^{\circ} \mathrm{C}$, the strength of the composite is preserved at a high level which is only lower than that of the previous composite. Since lower powder is needed, this is also an effective forming method of preparing this sort of particle reinforced composite in view of saving energies. When the green compact of the composite is hot-pressed at a temperature only below the solidus temperature, $\mathrm{SiC}$ particles are clustered in the matrix as impurities. Correspondingly, the $\mathrm{Al} / \mathrm{SiC}$ interfacial bond is rather weak, resulting in the poor properties including the strength, elongation and elastic modulus of the composite[7]. As the green compact is hot-pressed and hot-extruded both at low temperatures, $\mathrm{SiC}$ particles disperse homogeneously in matrix. However, the exposed $\mathrm{SiC}$ particles in the matrix indicate that the interfacial bond is not strong enough to resist the tensile, and the plastic deformation of $\mathrm{Al}$ matrix dominates the fracture behavior of the composite. Thus, the strength of the composite is low while the ductility is high[7]. As the green compact is hot-pressed at low temperature and hot-extruded at a temperature little higher than the solidus temperature, the $\mathrm{SiC} / \mathrm{Al}$ interfacial bond is strong with high strength $\mathrm{Al}$ matrix, resulting that much higher stress is needed to break the $\mathrm{SiC} / \mathrm{Al}$ interfaces. Under the condition that the $\mathrm{SiC} / \mathrm{Al}$ interfacial bond is strong, the $\mathrm{SiC}$ particles bear too much stress and crack during the load transferring, especially the particle corners are easy to fracture due to the stress concentration, explaining the phenomena that small broken $\mathrm{SiC}$ particles as well as large ones deposit in the fracture surfaces[8]. Due to the strong interfacial bond, the volume of Al matrix participating in deformation reduces and the Al matrix near to the depositions undergoes severe plastic deformation. As a result, the strength and elastic modulus of the composite are high while the elongation to failure decreases lightly[7]. In the case that the green compact is hot-pressed and hot-extruded both at higher temperatures, the $\mathrm{SiC} / \mathrm{Al}$ interfacial bond formed by atomic diffusion is very strong while the strength of matrix decreases. The fracture process occurs mainly in $\mathrm{Al}$ matrix and fewer broken or de-bonded $\mathrm{SiC}$ particles are found in the fracture surfaces, reflecting that the strength of the composite is low while the elongation is high[7].

\section{Conclusions}

In the current work, the effects of forming temperatures of hot pressing and hot extrusion preparing $12 \% \mathrm{SiCp} / \mathrm{Al}$ composite by $\mathrm{PM}$ route have been investigated. From the experimental results and the theoretical analysis, some conclusions are made as follows:(1) The procedures of hot pressing and hot extrusion are needed to produce $\mathrm{SiCp} / \mathrm{Al}$ composites in a PM route, and hot extrusion strongly affects the mechanical properties of composites;(2)The temperatures of hot pressing and hot extrusion have few effects on the elastic modulus of the composites; (3)When the green compacts is hot-pressed at a temperature little higher than the solidus temperature and hot-extruded at a low temperature, the strength of the composite is at the highest level with the strongly bonded SiC/Al interfaces; in the view of saving energies in industry, the method of hot-pressed at low temperature and hot-extruded at semi-solid state is also practicable; (4)If the forming 
temperatures of hot-pressed and hot-extruded in the preparation of the $12 \% \mathrm{SiCp} / 6066 \mathrm{Al}$ composite are $560^{\circ} \mathrm{C}$ and $430^{\circ} \mathrm{C}$ respectively, the strength of the composition is the highest and the composition exhibits a high level plasticity.

\section{Acknowledgements}

Subject supported by the National Natural Science Foundation of China (Grant No. 51171156) and the Fundamental Research Funds for the Central Universities of Ministry of Education of China (Grant No. XDJK2014C008)

\section{References}

1. D. J. Lloyd, Particle reinforced aluminum and magnesium matrix composites, Int. Mater. Rev., 1994, 39, 1-23.

2. A. P. Divecha, S. G. Fishman, S. D. Karmarkar, Silicon carbide reinforced aluminum-a formable composite, J. Met., 1981, 33, 12-17.

3. J. Zhou, A. T. Drużdżel, The effect of extrusion parameters on the fretting wear resistance of Al-based composites produced via powder metallurgy, J. Mater. Sci., 1999, 34, 5089-5097.

4. J. J. Lewandowski, C. Liu, et al, Effect of matrix microstructure and particle distribution on fracture of aluminum metal matrix composite, Mater. Sci. Eng. A, 1989, 107, 241-255.

5. F. Tang, I. E. Anderson, S. B. Biner, Solid state sintering and consolidation of Al powders and A 1 matrix composites, J. Light Met., 2002, 2, 204-214.

6. L. M. Thamlm, Effects of reinforcement volume fraction on the evolution of reinforcement size during the extrusion of Al-SiC composites, Mater. Sci. Eng. A, 2002, 326, 355-363.

7. K. M. Prewo and J. J. Brennan, High-strength silicon carbide fibre-reinforced glass-matrix composites, J. Mater. Sci., 1980, 15, 463-468.

8. S. K. Thakur, B. K. Dhindaw, The influence of interfacial characteristics between $\mathrm{SiC}_{\mathrm{p}}$ and $\mathrm{Mg} / \mathrm{Al}$ metal matrix on wear, coefficient of friction and microhardness, Wear, 2001, 247, 191-201. 